\title{
Healthy behaviours and abdominal adiposity in adolescents from southern Italy
}

\author{
Paola laccarino Idelson' ${ }^{1}$, Luca Scalfi ${ }^{2}$, Nicola Vaino ${ }^{3}$, Sara Mobilia', \\ Concetta Montagnese ${ }^{2}$, Adriana Franzese ${ }^{1}$ and Giuliana Valerio ${ }^{3, *}$ \\ 'Dipartimento di Pediatria, Università degli Studi di Napoli Federico II, Napoli, Italia: ${ }^{2}$ Dipartimento di Scienza \\ degli Alimenti, Università degli Studi di Napoli Federico II, Napoli, Italia: ${ }^{3}$ Dipartimento di Studi delle Istituzioni \\ e dei Sistemi Territoriali, Università degli Studi di Napoli Parthenope, Via Medina 40, 80133 Napoli, Italia
}

Submitted 19 April 2012: Final revision received 7 December 2012: Accepted 11 December 2012: First published online 28 January 2013

\begin{abstract}
Objective: The present study aimed to evaluate the prevalence of meeting health recommendations on diet and physical activity (having breakfast, eating fruit and vegetables, consumption of milk/yoghurt, performing moderate-to-vigorous physical activity, limiting television watching) and to assess junk snack food consumption in adolescents from southern Italy. The association between healthy behaviours and abdominal adiposity was also examined.

Design: In a cross-sectional protocol, anthropometric data were measured by trained operators while other data were collected through a structured interview. Setting: Three high schools in Naples, Italy.

Subjects: A sample of 478 students, aged 14-17 years, was studied.

Results: The proportion of adolescents who met each of the health recommendations varied: $55 \cdot 4 \%$ had breakfast on $\geq 6 \mathrm{~d}$ /week; $2.9 \%$ ate $\geq 5$ servings of fruit and vegetables/d; $1.9 \%$ had $\geq 3$ servings of milk/yoghurt daily; $13.6 \%$ performed moderate-to-vigorous physical activity for $\geq 60 \mathrm{~min} / \mathrm{d}$; and $46 \cdot 3 \%$ watched television for $<2 \mathrm{~h} / \mathrm{d}$. More than $65 \%$ of adolescents consumed $\geq 1$ serving of junk snack foods/d. Only $5 \%$ fulfilled at least three recommendations. Healthy habits tended to correlate with each other. As the number of health recommendations met decreased, the percentage of adolescents with high abdominal adiposity (waist-to-height ratio $\geq 0 \cdot 5$ ) increased. The trend was not significant when the proportion of overweight/obese adolescents was considered. Logistic regression analysis indicated that male gender and watching television for $\geq 2 \mathrm{~h} / \mathrm{d}$ were independently associated with a higher waist-to-height ratio.

Conclusions: Most adolescents failed to meet the five health recommendations considered. Male gender and excessive television watching were associated with abdominal adiposity.
\end{abstract}

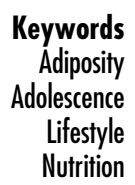

'Unhealthy diets and physical inactivity are key risk factors for the major non communicable diseases such as cardiovascular diseases, cancer, and diabetes.' Global Strategy on Diet, Physical Activity and Health, 2004

The lifestyle of individuals is very vulnerable to negative influences during adolescence, which is a crucial period of life when both major physical and psychological changes occur. Overall, there is a worldwide trend to adopt unhealthy behaviours ${ }^{(1,2)}$; for instance, both the Health Behaviour in School-aged Children (HBSC), a WHO collaborative cross-national survey in European countries $^{(3)}$, and the Youth Risk Behaviour Surveillance System (YRBSS) in the USA ${ }^{(4)}$ have indicated that skipping breakfast, low consumption of fruit and vegetables, high consumption of junk foods and increased sedentary activities are often observed in adolescents of both genders.

The risks associated with unhealthy behaviours related to diet and physical activity begin in childhood and build up throughout life ${ }^{(5)}$. During adolescence, diet may affect health status also in the short term, for instance by increasing adiposity and negatively affecting cardiovascular risk factors $^{(6)}$; similarly, sedentary behaviours and low physical activity are associated with excess body fat, hypertension and high cholesterol levels ${ }^{(7)}$.

Meeting health recommendations is expected to improve quality of life and to reduce the incidence of chronic diseases ${ }^{(8-10)}$. Adolescents' behaviours can be modified through a number of different strategies, for example communication campaigns and educational counselling $^{(11)}$ following the most common national ${ }^{(12)}$ and 
international recommendations ${ }^{(9,13,14)}$ such as: (i) having breakfast; (ii) consumption of $\geq 5$ servings of fruit and vegetables/d; (iii) consumption of $\geq 3$ servings of milk/ yoghurt daily; (iv) practice of moderate-to-vigorous physical activity (MVPA) for $\geq 60 \mathrm{~min} / \mathrm{d}$; and (v) limiting watching television (TV) to $<2 \mathrm{~h} / \mathrm{d}$.

Notwithstanding, little is known in adolescents about either the clustering of dietary and physical activity behaviours or their effects on health outcomes ${ }^{(15,16)}$ and surrogate end points. Among the latter, waist circumference (WC), a widely recognized marker of abdominal fat, is of particular practical interest because it is a predictor of metabolic and cardiovascular risks in adults and children $^{(17,18)}$. As a matter of fact, WC and waist-to-height ratio (WHtR) are both able to identify children with a higher metabolic and cardiovascular risk better than BMI-for-age or skinfold thickness ${ }^{(19-21)}$. While WC has been shown to be related to each healthy behaviour ${ }^{(22-25)}$, no data are available regarding the association with clustered behaviours.

The major aims of the present study were to: (i) evaluate the prevalence of meeting recommendations for breakfast consumption, fruit and vegetable intake, milk/yoghurt consumption, MVPA levels and TV watching in a sample of adolescents from southern Italy; and (ii) assess in these adolescents the association between meeting health recommendations and abdominal adiposity. As a secondary end point, junk snack food consumption and its correlation with unhealthy behaviours were assessed.

\section{Methods}

\section{Participants}

The study population was derived from a clusterrandomized sample of high-school students attending the second and third grade, participating in a study on the prevention of eating disorders (DiCAEv) in adolescence. That study took place in three high schools in Naples (Campania region, Italy) between March 2007 and December 2009. The sample included Caucasian individuals belonging to all socio-economic classes (according to parental educational level) and was representative of the school population of the Campania region ${ }^{(1)}$. The adolescents' parents or guardians were fully informed about the objectives and methods of the study and signed a consent form. Also the adolescents provided their written assent. Study procedures were carried out according to the guidelines laid down in the Declaration of Helsinki and approved by academic and scholastic institution boards. Inclusion criteria were: (i) age between 14 and 17 years and (ii) consent to participate. Six hundred and eightyseven adolescents were available to be recruited, but only 550 families gave their consent to participate in the study (80\%); adolescents with missing data on any of the independent variables considered in the survey were excluded ( $n$ 72). Therefore a total of 478 adolescents were finally evaluated (participation rate $86.9 \%$ ).

\section{Measures}

Anthropometry

A portable scale (Seca model 813, Hamburg, Germany) was used to measure weight to the nearest $0 \cdot 1 \mathrm{~kg}$, with shoes and heavy clothing removed. Height was measured to the nearest $0 \cdot 1 \mathrm{~cm}$ using a portable stadiometer (Seca model 220). BMI $\left(\mathrm{kg} / \mathrm{m}^{2}\right)$ was calculated as body weight divided by the square of height. WC was measured at the narrowest point between the lower costal border and the iliac crest using a non-extensible steel tape (Seca model 200). Measures of height and waist were taken three times and the mean value was considered for data analysis. WHtR, a marker of abdominal fat deposition independent of age ${ }^{(21)}$, was calculated and the cut-point of $\geq 0.5$ was used to identify adolescents with high abdominal adiposity ${ }^{(26)}$. Categories of overweight (OW) and obesity (OB) were defined according to the BMI thresholds proposed by Cole et $a l^{(27)}$ for international comparisons, where the cut-off points for OW and OB are smooth sex-specific BMI centiles, constructed to match the values of $25 \cdot 0$ and $30 \cdot 0 \mathrm{~kg} / \mathrm{m}^{2}$, respectively, at age 18 years. Parental education level was considered as a proxy index of socio-economic status.

\section{Dietary intake}

In the present study, the consumption of breakfast (d/week) and that of four food items (fruit, vegetables, milk, yoghurt products) was explored. Usual dietary intake was assessed through an FFQ administered by interview by two trained nutritionists. For each food item, respondents were asked to indicate the frequency of consumption per day, per week or per month. Never and seldom were also included and considered as 'zero'. All reported numbers were converted to daily frequency (servings/d). The daily intake for each food group (fruit and vegetables; milk and yoghurt) was calculated by summing up the frequency of consumption of fruit plus vegetables or milk plus yoghurt. In the same way, the consumption (servings/d) of snack foods rich in fat and/or added sugars, such as crisps or chocolate bars (defined as junk snack foods ${ }^{,(28)}$ ), was also assessed. Participants were classified as meeting each dietary recommendation when they consumed: breakfast on $\geq 6 \mathrm{~d} /$ week, $\geq 5$ servings of fruit and vegetables/d and $\geq 3$ servings of milk/yoghurt daily ${ }^{(9,12,13)}$.

\section{Physical activity}

The modified long version of the International Physical Activity Questionnaire (IPAQ), as proposed by the HELENA (Healthy Lifestyle in Europe by Nutrition in Adolescence) study ${ }^{(29,30)}$ and adapted into Italian according to the IPAQ committee guidelines (http://www.ipaq.ki.se/ cultural.htm), was administered by trained operators. The questionnaire for adolescents focuses on four 
domains: (i) school-related physical activity (including activity during physical education classes and breaks); (ii) transportation; (iii) housework; and (iv) leisure time. The housework domain included only one question (compared with three in the original IPAQ) about physical activities in the garden or at home. For each of the four domains, the number of days per week and the number of physical activity periods per day ( $\geq 10 \mathrm{~min}$ of physical activity) were recorded. Outcome measures were average minutes of walking, moderate or vigorous activities per day; the sum of moderate and vigorous activities was computed to obtain minutes of MVPA per day. Participants were classified as meeting physical activity recommendations if they performed MVPA for $\geq 60 \mathrm{~min} / \mathrm{d}^{(14)}$.

\section{Sedentary behaviours}

The study also included a questionnaire assessment regarding daily hours spent in TV watching and computer or video game use. Average time spent watching TV (h/d) was used as a proxy for unhealthy sedentary behaviour because it is considered an important determinant of OW in adolescence compared with video game and computer use $^{(31)}$. Participants were classified as meeting the specific recommendation if they limited TV watching to $<2 \mathrm{~h} / \mathrm{d}^{(14)}$.

\section{Statistical analysis}

All statistical analyses were performed using the SPSS statistical software package version $18 \cdot 0$. The level of significance was set at $P<0 \cdot 05$. Variables were not normally distributed. Descriptive statistics, including medians, 25th and 75th percentiles, frequencies and percentages, were used to describe demographic and anthropometric characteristics of participants as well as healthy lifestyle behaviours. The non-parametric Mann-Whitney $U$ test was used to compare differences in age, height, weight, BMI, WC and WHtR between genders. The Spearman's rank correlation test was performed to evaluate whether healthy lifestyle behaviours and junk snack food consumption correlated with each other. The $\chi^{2}$ test was used to compare proportions for parental education levels or selected health behaviours between genders. The $\chi^{2}$ test for trend was used for analysis of proportions between a binary variable (OW/OB status; $\mathrm{WHtR} \geq 0.5)$ and an ordered categorical variable (number of risk factors). Finally, binary logistic regression analysis was performed to evaluate associations of each of the selected health recommendations with WHtR, controlling for age and gender.

\section{Results}

Demographic and anthropometric characteristics Demographic and anthropometric characteristics of the adolescents are shown in Table 1. No difference in BMI was found between genders, while WC and WHtR were higher in boys than girls. OW prevalence was higher in boys than girls (29.9\% v. 19.7\%, respectively; $P<0 \cdot 01$ ), while $\mathrm{OB}$ prevalence did not differ between genders $(9 \cdot 8 \% v \cdot 6.9 \%$, respectively; $P=0 \cdot 2)$. WHtR was $\geq 0.5$ in $23 \cdot 8 \%$ of boys and $10 \cdot 3 \%$ of girls $(P<0 \cdot 01)$.

\section{Meeting bealth recommendations}

As median (25th-75th percentile) values, adolescents had breakfast on $7(1-7) \mathrm{d}$ /week, consumed $1.6(1 \cdot 0-2 \cdot 7)$

Table 1 Demographic and anthropometric characteristics of the study population: adolescents aged 14-17 years ( $n$ 478) attending three high schools in Naples, Italy, March 2007 to December 2009

\begin{tabular}{|c|c|c|c|c|c|c|c|}
\hline & \multicolumn{2}{|r|}{ Total $(n 478)$} & \multicolumn{2}{|r|}{ Boys ( $n$ 204) } & \multicolumn{2}{|r|}{ Girls (n 274) } & \multirow[b]{2}{*}{$P^{*}$} \\
\hline & Median & 25th-75th percentile & Median & 25th-75th percentile & Median & 25th-75th percentile & \\
\hline Age (years) & $16 \cdot 32$ & $15 \cdot 63-16 \cdot 78$ & $16 \cdot 04$ & $15 \cdot 43-16 \cdot 75$ & $16 \cdot 44$ & $15 \cdot 87-16 \cdot 82$ & $<0.001$ \\
\hline Height $(\mathrm{cm})$ & $165 \cdot 02$ & $159 \cdot 43-172 \cdot 16$ & $173 \cdot 65$ & $168 \cdot 85-178 \cdot 45$ & $160 \cdot 62$ & $157 \cdot 14-165 \cdot 00$ & $<0.001$ \\
\hline Weight (kg) & 63.25 & $55 \cdot 94-72 \cdot 42$ & $69 \cdot 27$ & $61 \cdot 40-80 \cdot 44$ & $58 \cdot 52$ & $52 \cdot 87-65 \cdot 96$ & $<0.001$ \\
\hline BMI $\left(\mathrm{kg} / \mathrm{m}^{2}\right)$ & $22 \cdot 81$ & $20 \cdot 81-25 \cdot 55$ & $22 \cdot 98$ & $20 \cdot 98-25 \cdot 92$ & $22 \cdot 66$ & $20 \cdot 64-25 \cdot 13$ & $0 \cdot 170$ \\
\hline WC $(\mathrm{cm})$ & $72 \cdot 00$ & $67 \cdot 35-77 \cdot 82$ & $77 \cdot 50$ & $71 \cdot 75-83 \cdot 77$ & $69 \cdot 60$ & $65 \cdot 50-73 \cdot 70$ & $<0.001$ \\
\hline \multirow[t]{2}{*}{ WHtR } & $0 \cdot 43$ & $0.41-0.47$ & $0 \cdot 44$ & $0.41-0.49$ & $0 \cdot 43$ & $0.41-0.46$ & $<0.050$ \\
\hline & $n$ & $\%$ & $n$ & $\%$ & $n$ & $\%$ & \\
\hline \multicolumn{7}{|l|}{ Father's education level } & 0.757 \\
\hline Elementary & 17 & $3 \cdot 6$ & 9 & $4 \cdot 4$ & 8 & $2 \cdot 9$ & \\
\hline Middle school & 117 & $24 \cdot 5$ & 52 & $25 \cdot 5$ & 66 & $24 \cdot 1$ & \\
\hline High school & 208 & $43 \cdot 5$ & 88 & $43 \cdot 1$ & 119 & $43 \cdot 4$ & \\
\hline Degree & 136 & $28 \cdot 4$ & 55 & $27 \cdot 0$ & 81 & $29 \cdot 6$ & \\
\hline \multicolumn{7}{|l|}{ Mother's education level } & $0 \cdot 202$ \\
\hline Elementary & 26 & $5 \cdot 4$ & 13 & $6 \cdot 4$ & 13 & $4 \cdot 7$ & \\
\hline Middle school & 106 & $22 \cdot 2$ & 52 & $25 \cdot 5$ & 54 & $19 \cdot 7$ & \\
\hline High school & 230 & $48 \cdot 1$ & 87 & $42 \cdot 6$ & 143 & $52 \cdot 2$ & \\
\hline Degree & 116 & $24 \cdot 3$ & 52 & $25 \cdot 5$ & 64 & $23 \cdot 4$ & \\
\hline
\end{tabular}

WC, waist circumference; WHtR, waist-to-height ratio.

The Mann-Whitney $U$ test was used to compare the differences in median values between genders, while the $\chi^{2}$ test was used to compare the proportion of parental education levels between genders.

${ }^{*}$ Statistical significance was taken as $P<0.05$ 
Table 2 Proportion of the study population who met each of the selected health recommendations: adolescents aged 14-17 years ( $n$ 478) attending three high schools in Naples, Italy, March 2007 to December 2009

\begin{tabular}{|c|c|c|c|c|c|c|c|}
\hline & \multicolumn{2}{|c|}{ Total $(n 478)$} & \multicolumn{2}{|c|}{ Males $(n$ 204) } & \multicolumn{2}{|c|}{ Females ( $n$ 274) } & \multirow[b]{2}{*}{$P^{*}$} \\
\hline & $n$ & $\%$ & $n$ & $\%$ & $n$ & $\%$ & \\
\hline Breakfast $\geq 6 \mathrm{~d} /$ week & 265 & $55 \cdot 4$ & 124 & $60 \cdot 8$ & 141 & $51 \cdot 5$ & 0.042 \\
\hline Fruit and vegetables $\geq 5$ servings/d & 14 & $2 \cdot 9$ & 8 & 3.9 & 6 & $2 \cdot 2$ & $0 \cdot 267$ \\
\hline Milk/yoghurt $\geq 3$ servings/d & 9 & $1 \cdot 9$ & 5 & $2 \cdot 5$ & 4 & $1 \cdot 5$ & 0.012 \\
\hline MVPA $\geq 60 \mathrm{~min} / \mathrm{d}$ & 65 & $13 \cdot 6$ & 26 & $12 \cdot 7$ & 39 & $14 \cdot 2$ & 0.639 \\
\hline TV watching $<2 \mathrm{~h} / \mathrm{d}$ & 221 & $46 \cdot 3$ & 83 & $40 \cdot 7$ & 138 & $50 \cdot 4$ & 0.036 \\
\hline
\end{tabular}

MPVA, moderate-to-vigorous physical activity; TV, television.

The $\chi^{2}$ test was used to compare the proportions meeting selected health recommendations between genders.

${ }^{*}$ Statistical significance was taken as $P<0.05$.

Table 3 Distribution of meeting multiple health recommendations in the study population: adolescents aged 14-17 years ( $n$ 478) attending three high schools in Naples, Italy, March 2007 to December 2009

\begin{tabular}{|c|c|c|c|c|c|c|}
\hline \multirow{2}{*}{$\begin{array}{l}\text { Number of health } \\
\text { recommendations met }\end{array}$} & \multicolumn{2}{|c|}{ Total $(n 478)$} & \multicolumn{2}{|c|}{ Males ( $n$ 204) } & \multicolumn{2}{|c|}{ Females ( $n$ 274) } \\
\hline & $n$ & $\%$ & $n$ & $\%$ & $n$ & $\%$ \\
\hline 0 & 103 & $21 \cdot 5$ & 38 & $18 \cdot 6$ & 65 & $23 \cdot 7$ \\
\hline 1 & 202 & $42 \cdot 3$ & 96 & $47 \cdot 1$ & 106 & 38.7 \\
\hline 2 & 149 & $31 \cdot 2$ & 62 & $30 \cdot 4$ & 87 & $31 \cdot 8$ \\
\hline 3 & 23 & $4 \cdot 8$ & 7 & $3 \cdot 4$ & 16 & $5 \cdot 8$ \\
\hline 4 & 1 & 0.2 & 1 & 0.5 & 0 & 0.0 \\
\hline 5 & 0 & 0.0 & 0 & 0.0 & 0 & 0.0 \\
\hline
\end{tabular}

servings of fruit and vegetables/d, consumed $1 \cdot 0(0 \cdot 3-1 \cdot 0)$ servings of milk/yoghurt daily, reported $22.9(11 \cdot 1-45 \cdot 7)$ min of MVPA/d and spent $2 \cdot 0(1 \cdot 0-2 \cdot 5) \mathrm{h}$ watching $\mathrm{TV} / \mathrm{d}$.

The proportion of adolescents meeting each of the selected health recommendations is shown in Table 2; $55.4 \%$ for having breakfast, $2.9 \%$ for eating fruit and vegetables, $1.9 \%$ for milk/yoghurt consumption $13.6 \%$ for performing MVPA and $46.3 \%$ for TV watching. No differences between genders were found, except that having breakfast and milk/yoghurt consumption that were slightly more frequent in boys. More than $65 \%$ of adolescents ate $\geq 1$ serving of junk snack foods/d (median $1 \cdot 14$, 25 th-75th percentile $0 \cdot 71-1 \cdot 86$ ), with no gender difference. The number of health recommendations met by the same individual was also considered (Table 3). About $21 \%$ of the sample did not meet any health recommendation, while only about $5 \%$ fulfilled three recommendations, and $<0.5 \%$ fulfilled four recommendations. No gender differences were found (Table 3).

Finally, healthy lifestyle behaviours and junk snack food consumption were correlated with each other; only significant results are reported here. There was a positive association between having breakfast and eating fruit and vegetables $(r=0.113, P<0.02)$; both of these eating behaviours were positively correlated with milk/yoghurt consumption ( $r=0.523, P<0 \cdot 001$ and $r=0 \cdot 134, P<0 \cdot 004$, respectively) and negatively correlated with eating junk snack foods $(r=-0 \cdot 173, \quad P<0 \cdot 001$ and $r=-0 \cdot 179$, $P<0 \cdot 001$, respectively). Watching TV was negatively correlated with having breakfast $(r=-0.093, P<0.05)$ and eating fruit and vegetables $(r=-0 \cdot 154, P<0 \cdot 01)$, while it was positively correlated with eating junk snack foods $(r=0 \cdot 186, P<0 \cdot 001)$. Total time spent in sedentary behaviours was negatively correlated with eating fruit and vegetables $(r=-0 \cdot 181, P<0 \cdot 001)$ and positively correlated with eating junk snack foods $(r=0 \cdot 244, P<0 \cdot 001)$.

\section{Relationships between meeting bealth recommendations and abdominal adiposity}

When the association between WHtR as outcome variable with each of the healthy lifestyle behaviours as independent variables was considered, the only positive relationship emerged with TV watching $(r=0 \cdot 118, P<0 \cdot 05)$. On the other hand, as the number of healthy recommendations met decreased, the percentage of adolescents with abdominal adiposity rose (Fig. $1, P<0 \cdot 002, \chi^{2}$ for trend). The trend was not significant for the prevalence of $\mathrm{OW} /$ OB $(P=0 \cdot 329)$. Having regular breakfast, performing $\geq 60 \mathrm{~min}$ of $\mathrm{MVPA} / \mathrm{d}$ and watching TV for $<2 \mathrm{~h} / \mathrm{d}$ represented the most frequent cluster of healthy lifestyle behaviours (89\%) in adolescents with $\mathrm{WHtR}<0.5$. Finally, the logistic regression model demonstrated that male gender (OR 2.560, 95\% CI 1.338, 4.892; $P<0 \cdot 005$ ) and watching TV for $\geq 2 \mathrm{~h} / \mathrm{d}$ (OR $2 \cdot 260$, 95\% CI $1 \cdot 154$, $4.427 ; P<0.02$ ) were the only independent variables positively associated with high WHtR values.

\section{Discussion}

The main results of the present study indicated that: adolescents living in Campania region only seldom meet 


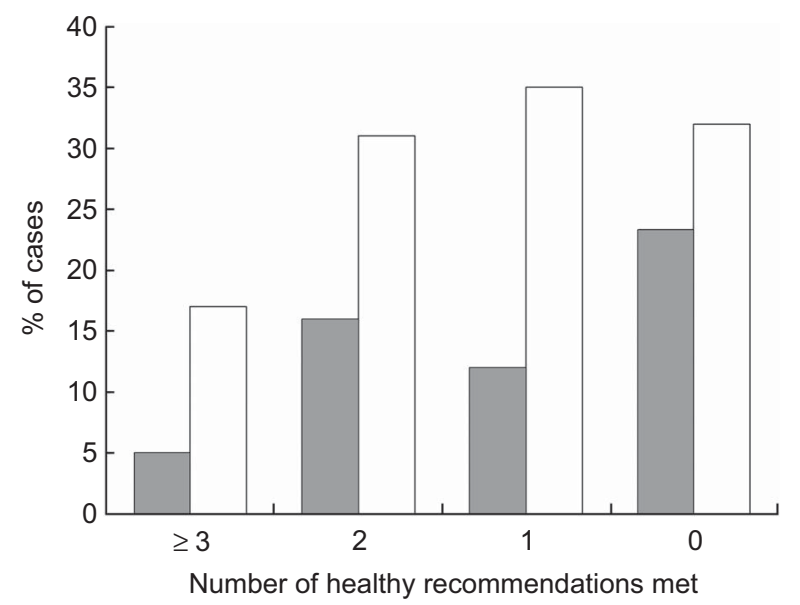

Fig. 1 Percentage of cases with abdominal adiposity (waist-toheight ratio $>0.5 ; \square$ ) or overweight/obesity $(\square)$ in the different categories of multiple healthy recommendations met among adolescents aged 14-17 years ( $n$ 478) attending three high schools in Naples, Italy, March 2007 to December 2009. The $\chi^{2}$ test for trend was used for the statistical analysis of proportions: as the number of healthy recommendations met decreased, the percentage of adolescents with abdominal adiposity rose $(P<0.002)$, while the trend was not significant for overweight/ obesity $(P=0.329)$

health recommendations on diet and physical activity; healthy behaviours are correlated with each other; and there is a positive association of male gender and TV watching with abdominal adiposity.

\section{Meeting bealth recommendations}

The present study has considered main dietary and physical activity recommendations as important determinants of present and future health ${ }^{(32-35)}$. First, the proportion of adolescents meeting each of the recommendations was evaluated. Skipping breakfast has been related in adolescence to irregular pattern of meals and junk food consumption $^{(36-38)}$, and it is also associated with an increased risk of excess body fat ${ }^{(39)}$. Consistent with previous studies $^{(1,40)}$, breakfast was consumed at least $6 \mathrm{~d} /$ week only by $55 \%$ of our sample and more frequently by boys than girls, as already observed in northern Italy and throughout Europe ${ }^{(41,42)}$. The consumption of fruit and vegetables is commonly promoted because they are nutrient-dense foods with a potential effect, even if relatively small, in protecting against adiposity in children ${ }^{(6)}$. In agreement with previous surveys $^{(1,43)}$ the average consumption of fruit and vegetables was very low in the adolescents studied, with only a low percentage of them $(2 \cdot 9 \%)$ consuming at least 5 servings/d. Another marker of a healthy diet is eating non-energy-dense dairy products ${ }^{(44)}$, which are an important source of calcium $^{(33)}$. In our sample only $1.9 \%$ of the adolescents met the guidelines for milk and yoghurt consumption, in line with previous data regarding our region ${ }^{(1)}$.

In addition to healthy dietary behaviours, lifestyle recommendations for adolescents promote physical activity and the reduction of sedentary behaviours, aiming for better physical fitness and psychological health ${ }^{(34)}$. In particular, low physical activity and excessive TV watching are both considered in adolescents as significant determinants of excess body fat and cardiometabolic risk factors $^{(34,35)}$. We evaluated physical activity using a wellestablished questionnaire (IPAQ) ${ }^{(30,34)}$. A threshold of $60 \mathrm{~min}$ of $\mathrm{MVPA} / \mathrm{d}$, chosen according to evidence-based recommendations ${ }^{(14)}$, was met by $13.6 \%$ of our sample with no gender difference. This value was slightly higher than that reported by the HBSC regional survey $(8 \cdot 1 \%)^{(1)}$, possibly because of the different methodology. On the other hand, similar results have been obtained, as compared with the HBSC regional survey ${ }^{(1)}$, with respect to the percentage of adolescents $(<50 \%)$ meeting the recommendation for TV watching.

Finally, the consumption of junk snack foods (sweet and savoury products) was also specifically assessed, because of its negative impact on diet quality ${ }^{(45)}$. Quite astonishingly, $>65 \%$ of our sample ate at least 1 serving of junk snack foods/d.

As far as we are aware, few papers have focused on the clustering of dietary, physical activity and sedentary behaviours in adolescents. First, we considered the selected health behaviours as dichotomized variables (meeting or not meeting health recommendations): only less than one adolescent out of twenty met three or four recommendations, with the most prevalent cluster represented by having breakfast, performing physical activity and limiting TV watching; while, on the other hand, more than one adolescent out of five did not meet any health recommendation. In a similar study on patterns of nutrition and physical activity behaviours in adolescents, Sanchez et $a l^{(16)}$ reported that only $2 \%$ of Spanish adolescents completely met the guidelines for diet (fat $<30 \%$ of total energy and fruit/ vegetables $>5$ servings/d), physical activity $(>60 \mathrm{~min} / \mathrm{d})$ and sedentary healthy behaviours (TV $<120 \mathrm{~min} / \mathrm{d}$ ).

Second, the five health behaviours (having breakfast, eating fruit and vegetables, consumption of milk/yoghurt, performing MVPA, limiting TV watching) were related to each other and with junk snack food consumption. There were significant correlations between the three dietary behaviours. Watching TV was inversely related to having breakfast or eating fruit and vegetables, while junk snack food intake not only negatively correlated with breakfast frequency, but was also positively related to TV watching, possibly because of concurrent eating and/or exposure to food advertising ${ }^{(46)}$. Although a direct comparison with previous data cannot be performed, since the behaviours considered were not strictly the same, a few studies have already confirmed that risk-related behaviours may coexist in young adolescents ${ }^{(47-49)}$.

\section{Meeting bealtb recommendations and abdominal adiposity}

WC, which is a marker of abdominal fat ${ }^{(18)}$, has been shown to be related to having breakfast ${ }^{(22)}$, fruit and 
vegetable consumption $^{(23)}$, physical activity ${ }^{(24)}$ and sedentary behaviours $^{(25)}$. In addition, mounting evidence has demonstrated the benefits of regular physical activity as treatment for abdominal obesity in association with energy restriction ${ }^{(50)}$

As far as we are aware, the present study is the first one that has evaluated and clearly demonstrated the association between meeting health recommendations and abdominal adiposity. As the number of health recommendations met decreased, the proportion of adolescents with abdominal adiposity increased (Fig. 1), while no significant trend was observed for the prevalence of OW/OB.

Taking into consideration also the above-mentioned relationships between TV watching and dietary behaviours, such as consumption of junk snack foods ${ }^{(46,51-53)}$, it is not surprising that the logistic regression analysis model also identified TV watching as an independent predictor of WHtR in our adolescents. On the contrary, we failed to demonstrate any association between total screen time (TV watching, video game and computer use) and WHtR $(r=0 \cdot 05)$, possibly because of the specific behavioural setting of the Neapolitan area (e.g. less time spent using computers).

Overall, the results of the present study are likely to depend on the criteria chosen for defining recommendations. Some healthy behaviours, such as having breakfast and limiting TV watching, more probably entered in the cluster of recommendations met just because they were the most prevalent. Thus, the results of the logistic regression analysis model cannot be interpreted in the sense that the role of fruit and vegetable consumption or MVPA in the prevention of abdominal adiposity should be denied.

We should acknowledge that the study has some limitations such as its cross-sectional design, the relatively narrow age range and the restriction to the urban setting in one southern region of Italy. On the other hand, the strengths of the study are that all data were collected by interview and carefully checked by trained nutritionists rather than self-reported; in addition, all anthropometric data were carefully measured rather than being reported.

\section{Conclusions}

The WHO recommends the implementation of strategies in order to face the multiple risks linked to unbalanced diet and sedentary lifestyle. Our study indicates that adolescents not often meet multiple health recommendations on diet and physical activity, confirming that there is a strong need for effective strategies to promote healthy behaviours during adolescence.

In particular, watching $\mathrm{TV}$ for $\geq 2 \mathrm{~h} / \mathrm{d}$ is the marker more strictly related to abdominal fat in adolescence. We suggest that the calculation of WHtR should be included in health surveillance systems, because not only it is a predictor of cardiovascular risk but also it is sensitive to the effect of unhealthy lifestyle.

\section{Acknowledgements}

Sources of funding: The work was funded by Regione Campania (delibera no. 1687 - 26/11/05). Conflicts of interest: None of the authors had any personal or financial conflict of interest. Ethics: The Ethics Committee of Federico II University approved the study protocol. Authors' contributions: P.I.I., L.S., A.F. and G.V. provided substantial contribution to the conception and design of the study. P.I.I., N.V., S.M. and C.M. were responsible for the field work of the survey, development of the database and uploading of the data. P.I.I. and G.V. did the analyses and drafted the manuscript. All authors read and approved the final version of the manuscript. Acknowledgements: The authors acknowledge Professor Adriana Vaio for her support and collaboration and the schools and pupils for their participation.

\section{References}

1. Mazzarella G \& Pizzuti R (editors) (2011) Stili di vita e salute dei giovani in età scolare. Rapporto sui dati regionali HBSC 2009-2010. Regione Campania. Napoli: Phoebus edizioni.

2. Moreno LA, Rodriguez G, Fleta J et al. (2010) Trends of dietary habits in adolescents. Crit Rev Food Sci Nutr 50, 106-112.

3. Currie C, Nic Gabhainn S, Godeau E et al. (editors) (2008) Inequalities in Young People's Health: HBSC International Report from the 2005/06 Survey. Health Policy for Children and Adolescents no. 5. Copenhagen: WHO Regional Office for Europe.

4. Centers for Disease Control and Prevention (2012) Youth risk behavior surveillance - United States, 2011. MMWR Surveill Summ 61, issue 4, 1-162.

5. World Health Organization (2010) Set of Recommendations on the Marketing of Foods and Non-Alcobolic Beverages to Children. Geneva: WHO; available at http://whqlibdoc.who.int/publications/2010/9789241500210_ eng.pdf

6. Davis MM, Gance-Cleveland B, Hassink S et al. (2007) Recommendations for prevention of childhood obesity. Pediatrics 120, Suppl. 4, S229-S253.

7. Freedman DS, Dietz WH, Srinivasan SR et al. (1999) The relation of overweight to cardiovascular risk factors among children and adolescents: the Bogalusa Heart Study. Pediatrics 103, 1175-1182.

8. Aarnio M (2003) Leisure-time physical activity in late adolescence. J Sports Sci Med 2, Suppl. 2, 1-42.

9. World Health Organization (2004) Global Strategy on Diet, Physical Activity and Health. Geneva: WHO; available at http://www.who.int/dietphysicalactivity/strategy/eb11344/ strategy_english_web.pdf

10. Kavey RE, Daniels SR, Lauer RM et al. (2003) American Heart Association guidelines for primary prevention of atherosclerotic cardiovascular disease beginning in childhood. Circulation 107, 1562-1566.

11. Evans WD, Uhrig J, Davis K et al. (2009) Methods to evaluate health communication and marketing campaigns. J Health Commun 14, 315-330.

12. Ministero delle Politiche Agricole e Forestali \& Istituto Nazionale di Ricerca per gli Alimenti e la Nutrizione (2003) Linee guida per una sana alimentazione italiana. http:// www.inran.it/files/download/linee_guida/lineeguida_intro.pdf (accessed 2003). 
13. US Department of Agriculture \& US Department of Health and Human Services (2010) Dietary Guidelines for Americans, 7th ed. Washington, DC: US Government Printing Office; available at http://www.cnpp.usda.gov/DGAs2010-Policy Document.htm

14. World Health Organization (2010) Global Recommendations on Physical Activity for Health. Geneva: WHO; available at http://whqlibdoc.who.int/publications/2010/ 9789241599979_eng.pdf

15. McKenna M, Taylor WC, Marks J et al. (1998) Current issues and challenges in chronic disease control. In Chronic Disease Epidemiology and Control, pp. 1-26 [R Brownson, $\mathrm{P}$ Remington and $\mathrm{J}$ Davis, editors]. Washington, DC: American Public Health Association/United Book Press.

16. Sanchez A, Norman GJ, Sallis JF et al. (2007) Patterns and correlates of physical activity and nutrition behaviors in adolescents. Am J Prev Med 32, 124-130.

17. Takami R, Takeda N, Hayashi M et al. (2001) Body fatness and fat distribution as predictors of metabolic abnormalities and early carotid atherosclerosis. Diabetes Care $\mathbf{2 4}$, 1248-1252.

18. Savva SC, Tornaritis M, Sedvva ME et al. (2000) Waist circumference and waist-to-height ratio are better predictors of cardiovascular disease risk factors in children than body mass index. Int $J$ Obes Relat Metab Disord 24, 1453-1458.

19. Saelens BE, Seeley RJ, van Schaick K et al. (2007) Visceral abdominal fat is correlated with whole-body fat and physical activity among 8 -y-old children at risk of obesity. Am J Clin Nutr 85, 46-53.

20. Freedman DS, Kahn HS, Mei Z et al. (2007) Relation of body mass index and waist-to-height ratio to cardiovascular disease risk factors in children and adolescents: the Bogalusa Heart Study. Am J Clin Nutr 86, 33-40.

21. Ashwell M, Gunn P \& Gibson S (2012) Waist-to-height ratio is a better screening tool than waist circumference and BMI for adult cardiometabolic risk factors: systematic review and meta-analysis. Obes Rev 13, 275-286.

22. Alexander KE, Ventura EE, Spruijt-Metz D et al. (2009) Association of breakfast skipping with visceral fat and insulin indices in overweight Latino youth. Obesity (Silver Spring) 17, 1528-1533.

23. Bradlee ML, Singer MR \& Qureshi MM (2010) Food group intake and central obesity among children and adolescents in the Third National Health and Nutrition Examination Survey (NHANES III). Public Health Nutr 13 797-805.

24. Klein-Platat C, Oujaa M, Wagner A et al. (2005) Physical activity is inversely related to waist circumference in $12-\mathrm{y}$ old French adolescents. Int J Obes (Lond) 29, 9-14.

25. Martinez-Gomez D, Rey-López JP, Chillón P et al. (2010) Excessive TV viewing and cardiovascular disease risk factors in adolescents. The AVENA cross-sectional study. BMC Public Health 10, 274.

26. Ashwell M \& Hieh SD (2005) Six reasons why the waistto-height ratio is a rapid and effective global indicator for health risks of obesity and how its use could simplify the international public health message on obesity. Int J Food Sci Nutr 56, 303-307.

27. Cole TJ, Bellizzi MC, Flegal KM et al. (2000) Establishing a standard definition for child overweight and obesity worldwide: international survey. BMJ 320, 1240-1243.

28. Anderson JW \& Patterson K (2005) Snack foods: comparing nutrition values of excellent choices and 'junk foods'. $J \mathrm{Am}$ Coll Nutr 24, 155-157.

29. Craig CL, Marshall AL, Sjostrom M et al. (2003) International physical activity questionnaire: 12-country reliability and validity. Med Sci Sports Exerc 35, 1381-1395.

30. Hagströmer M, Bergman P, De Bourdeaudhuij I et al. (2008) Concurrent validity of a modified version of the International
Physical Activity Questionnaire (IPAQ-A) in European adolescents: The HELENA Study. Int J Obes (Lond) 32, Suppl. 5, S42-S48.

31. Rey-López JP, Vicente-Rodríguez G, Biosca $\mathrm{M}$ et al. (2008) Sedentary behaviour and obesity development in children and adolescents. Nutr Metab Cardiovasc Dis 18, 242-251.

32. Edwards JU, Mauch L \& Winkelman MR (2011) Relationship of nutrition and physical activity behaviours and fitness measures to academic performance for sixth graders in a midwest city school district. I Sch Health $\mathbf{8 1}$, 65-73.

33. Ross CA (2011) The 2011 report on dietary reference intakes for calcium and vitamin D from the Institute of Medicine: what clinicians need to know. J Clin Endocrinol Metab 96, 53-58.

34. Strong WB, Malina RM, Blimkie CJ et al. (2005) Evidence based physical activity for school-age youth. J Pediatr 146, 732-737.

35. Crespo CJ, Smit E, Troiano RP et al. (2001) Television watching, energy intake, and obesity in US children: results from the third National Health and Nutrition Examination Survey, 1988-1994. Arch Pediatr Adolesc Med 155, 360-365.

36. Hoyland A, Dye L \& Lawton CL (2009) A systematic review of the effect of breakfast on the cognitive performance of children and adolescents. Nutr Res Rev 22, 220-243.

37. Kant AK, Andon MB, Angelopoulos TJ et al. (2008) Association of breakfast energy density with diet quality and body mass index in American adults: National Health and Nutrition Examination Surveys, 1999-2004. Am J Clin Nutr 88, 1396-1404.

38. Affenito SG, Thompson DR, Barton BA et al. (2005) Breakfast consumption by African-American and white adolescent girls correlates positively with calcium and fiber intake and negatively with body mass index. $J$ Am Diet Assoc 105, 938-945.

39. Szajewska H \& Ruszczynski M (2010) Systematic review demonstrating that breakfast consumption influences body weight outcomes in children and adolescents in Europe. Crit Rev Food Sci Nutr 50, 113-119.

40. Hallstrom L, Vereecken CA, Ruiz JR et al. (2011) Breakfast habits and factors influencing food choices at breakfast in relation to socio-demographic and family factors among European adolescents. The HELENA Study. Appetite 56, 649-657.

41. Vanelli M, Iovane B, Bernardini A et al. (2005) Breakfast habits of 1202 Northern Italian children admitted to a summer sport school. Breakfast skipping is associated with overweight and obesity. Acta Biomed 76, 79-85.

42. Pearson N, Atkin AJ, Biddle SJH et al. (2009) Patterns of adolescent physical activity and dietary behaviours. Int $J$ Behav Nutr Phys Act 6, 45.

43. Larson N, Neumark-Sztainer D, Hannan PJ et al. (2007) Trends in adolescent fruit and vegetable consumption 1999-2004: Project EAT. Am J Prev Med 32, 147-150.

44. American Dietetic Association (2007) Childhood Overweight Evidence Analysis Project: Updated 2006. http:// www.adaevidencelibrary.com/topic.cfm?cat=1046 (accessed June 2007).

45. Capewell S \& McPherson K (2010) Cut junk food, says NICE guidance on cardiovascular disease prevention. Heart 96, 1762-1763.

46. Council on Communications and Media, Strasburger VC (2011) Children, adolescents, obesity, and the media. Pediatrics 128, 201-208.

47. Pearson N \& Biddle SJ (2011) Sedentary behavior and dietary intake in children, adolescents, and adults a systematic review. Am J Prev Med 41, 178-188. 
48. Seghers J \& Rutten C (2010) Clustering of multiple lifestyle behaviours and its relationship with weight status and cardiorespiratory fitness in a sample of Flemish 11- to 12year-olds. Public Health Nutr 13, 1838-1846.

49. Dumith SC, Muniz LC, Tassitano RM et al. (2012) Clustering of risk factors for chronic diseases among adolescents from Southern Brazil. Prev Med 54, 393-396.

50. Kim YM \& Lee SJ (2009) Physical activity and abdominal obesity in youth. Appl Physiol Nutr Metab 34, 571-581.
51. Francis LA, Lee Y \& Birch LL (2003) Parental weight status and girls' television viewing, snacking, and body mass indexes. Obes Res 11, 143-151.

52. Matheson DM, Killen JD, Wang Y et al. (2004) Children's food consumption during television viewing. Am J Clin Nutr 79, 1088-1094.

53. Harrison K \& Marske AL (2005) Nutritional content of foods advertised during the television programs children watch most. Am J Public Health 95, 1568-1574. 